\title{
Dielectric Constant of nano- CCTO / Epoxy Composite
}

\author{
Logean Q. Ibrhium $^{1^{*}}$, Mukhlis M. Ismail ${ }^{2}$, Balkees.M.Aldabbagh ${ }^{3}$ \\ 'Medical, Engineering / Nahriun University, Iraq) \\ 2 (Physical, School of Applied Sciences /University of Technology, Iraq) \\ ${ }^{3}$ (Material, School of Applied Sciences /University of Technology, Iraq)
}

\begin{abstract}
Nanocrystalline multiphase $\mathrm{CaCu}_{3} \mathrm{Ti}_{4} \mathrm{O}_{12}$ (CCTO) was prepared using $\mathrm{Ca}\left(\mathrm{NO}_{3}\right)_{2} .4 \mathrm{H}_{2} \mathrm{O}$, $\mathrm{Cu}\left(\mathrm{NO}_{3}\right)_{2} \cdot 3 \mathrm{H}_{2} \mathrm{O}$, TiO $\mathrm{T}_{2}$ and $\mathrm{C}_{2} \mathrm{H}_{2} \mathrm{O}_{4} \cdot 2 \mathrm{H}_{2} \mathrm{O}$. The X-Ray differection and SEM analysed of the prepared CCTO powder sintered at $900^{\circ} \mathrm{C}$ and $950^{\circ} \mathrm{C}$.

A homogeneous ceramics-polymer nanocomposites consisting of CCTO particles as fillers and epoxy polymer as matrix have been prepared using a casting process. The nanocomposites exhibit enhanced dielectric constant and dielectric loss.

Dielectric properties of CCTO ceramics were characterized in a broad frequency range (100 Hz-1 $\mathrm{MHz})$ and at a temperature ranged from $25^{\circ} \mathrm{C}$ to $150^{\circ} \mathrm{C}$.

As a result of increasing the content of CCTO, the dielectric constant and dielectric loss of composites are increased.
\end{abstract}

The increase of dielectric loss at high frequencies is due to the relaxation process in the polymer matrix.

Keywords: Dielectric Constant, CCTO, Nanopartical.

\section{Introduction}

$\mathrm{CaCu}_{3} \mathrm{Ti}_{4} \mathrm{O}_{12}$ (CCTO) has been extensively investigated recently because of its giant dielectric constant, with values up to $10^{5}$ at room temperature [1-2]. The large dielectric constant is very unusual because CCTO is not a ferroelectric. Because its dielectric properties depend primarily on the ceramic microstructure (such as the average grain size and pellet density) and processing conditions (such as the oxygen partial pressure, sintering temperature, and cooling rate), an intrinsic mechanism for the giant dielectric constant seems to be excluded. Most studies have attributed the giant value to the Maxwell-Wagner effect (internal barrier layer capacitor) at the interface of grains and grain boundaries, [3-4] while Lunkenheimer et al. believe they are due to electrode polarization effects.[5-6] In order to understand the origin of giant dielectric response in CCTO, extensive work has been carried out and various mechanisms have been proposed [7]. But, the generally accepted mechanism is an internal barrier layer capacitor (IBLC) model, which consists of semi conducting grains and insulating grain boundaries. Chemical and mechanical properties are very important for application of dielectric device development. It is being widely used in the electronic industries to manufacture electronic components such as multilayer capacitor (MLCC), microwave devices; electronic devices in automobiles and aircrafts embedded sensors and electric energy storage devices [8-9].

Epoxy resins are the most commonly used thermoset plastic in polymer matrix composites. Epoxy resins are a family of thermoset plastic materials which do not give off reaction products when they cure and so have low cure shrinkage. They also have good adhesion to other materials, good chemical and environmental resistance, good chemical properties and good insulating properties. The epoxy resins are generally manufactured by reacting epichlorohydrin with bisphenol. Different resins are formed by varying proportions of the two: as the proportion of epichlorohydrin is reduced the molecular weight of the resin is increased [10].

In recent years, there has been an increasing interest on high dielectric constant flexible particulate composites made up of a ferroelectric ceramic and a polymer for high density energy storage and capacitor applications [11]. However, the dielectric constant of such polymer based composites is rather low (about 50) because of the lower dielectric constant of the matrix (usually below 10) [12].

New generation of ultrahigh dielectric as $\mathrm{CaCu}_{3} \mathrm{Ti}_{4} \mathrm{O}_{12}$ (CCTO) can be used in order to obtain composites with a better performance.

A number of theoretical studies and experimental observations has attempted to elucidate the remarkable (ultra high) dielectric properties of CCTO perovskite-like material, where this materials have demonstrated to have dielectric constant as high as 50000 .

\section{Experimental}

The CCTO powder prepared by co-precipitation method using $\mathrm{Ca}\left(\mathrm{NO}_{3}\right)_{2} \cdot 4 \mathrm{H}_{2} \mathrm{O}, \mathrm{Cu}\left(\mathrm{NO}_{3}\right)_{2} \cdot 3 \mathrm{H}_{2} \mathrm{O}, \mathrm{TiO}_{2}$ and $\mathrm{C}_{2} \mathrm{H}_{2} \mathrm{O}_{4} \cdot 2 \mathrm{H}_{2} \mathrm{O}$ at $900{ }^{\circ} \mathrm{C}$ and $950^{\circ} \mathrm{C}$ for $2 \mathrm{~h}$ with an intermittent grinding. 
The composite samples (epoxy/ CCTO) for different volume frication $(0.004,0.006,0.02$, and 0.06$)$ at $900^{\circ} \mathrm{C}$ and $950^{\circ} \mathrm{C}$ were prepared as a second stage.

To prepare epoxy used in the experiment; resin and hardener were mixed in 3:1 volume ratio. For fabricating a composite under study, the CCTO powder was added to the previously prepared epoxy. The resultant product was mixed thoroughly by ultrasonication to have the uniform distribution of CCTO particles in the matrix at one hour.

The samples were cured at $500 \mathrm{C}$ for $2 \mathrm{~h}$ to get well shaped hard discs $(10-20 \mathrm{~mm}$ in diameter and 2-3 $\mathrm{mm}$ in thickness). A series of CCTO/epoxy composite with CCTO volume varying from $0 \%$ to $0.04 \%, 0.06 \%$, $0.2 \%$ and $0.6 \%$ were fabricated. For dielectric constant measurements, samples were polished using emery papers containing successively finer abrasives to achieve perfectly parallel and smooth surfaces. The surfaces of the disc were painted with silver paste and cured at $500 \mathrm{C}$. The copper leads were glued on to the surface for making capacitance measurements. These were carried out on the sample as a function of frequency $(50 \mathrm{~Hz}-$ 5.000.000 Hz). Dielectric constants were evaluated by taking the dimensions of the sample into account.

The disc samples (sintering CCTO powder at $950^{\circ} \mathrm{C}$ ) were polished to produce at uniform surface and electrode with silver paint. After that the dielectric constant of composite treatment temperature for $20^{\circ} \mathrm{C}$ to $150^{\circ} \mathrm{C}$ were tested.

\section{Result and discussion}

Fig (1) show that the result of XRD for CCTO powder prepared at $900^{\circ} \mathrm{C}$ for $2 \mathrm{~h}$. Fig (1) confirms that the CCTO phase is predominated with subsidence of all peaks for other phases. The powder is an important value to co-precipitate of $\mathrm{Ti}, \mathrm{Cu}$, and $\mathrm{Ca}$ compounds.

Fig.(1) XRD patten of the calcined powder at $900^{\circ} \mathrm{C}$

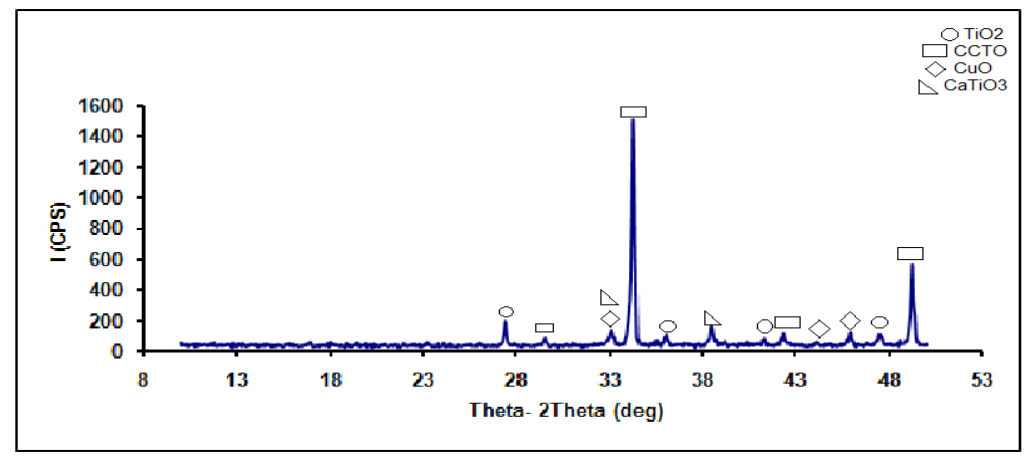

Fig.(2) shows the SEM photos of the CCTO powder prepared at $900^{\circ} \mathrm{C}$ for $2 \mathrm{~h}$. During from SEM result Particle size of CCTO powder vary from 200 to $400 \mathrm{~nm}$.
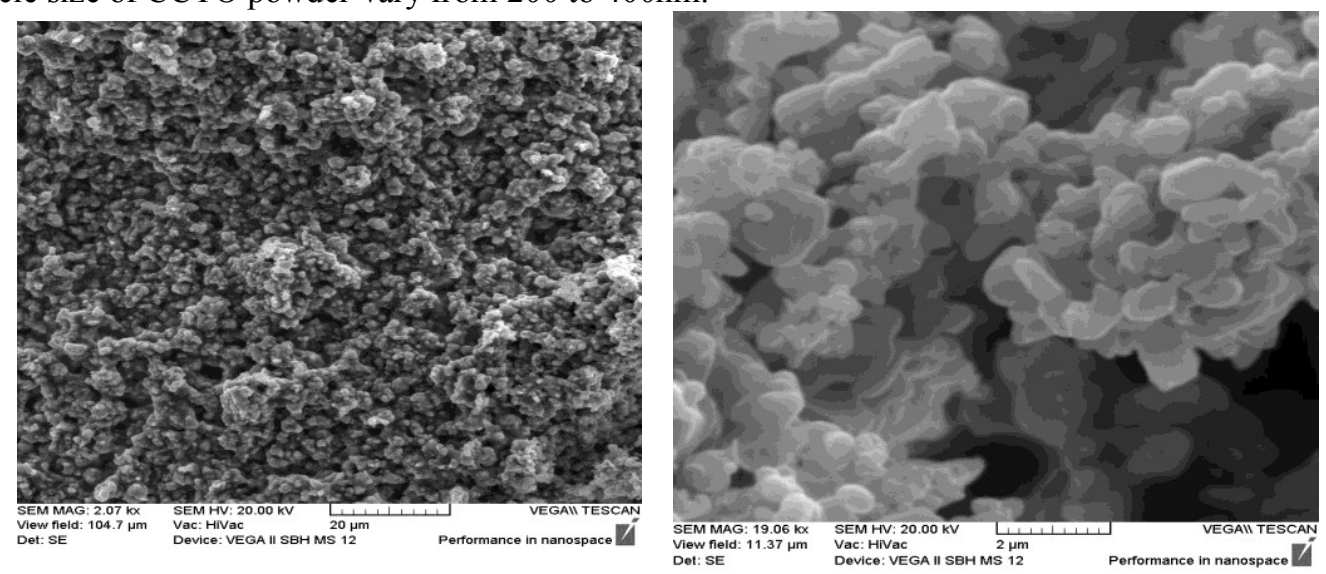

Fig.(2) SEM of calcined CCTO powder

The frequency dependence of the dielectric constant and dielectric loss for as-cast and subsequently annealed composites at room temperature are shown Fig. (3), where the composites with different CCTO contents $(0,0.004,0.006,0.02,0.06)$ are presented and the content of CCTO is identified in figure. The results show that the dielectric constant of the composite increase as a result of increasing the content of CCTO. The 
change, however, in the dielectric loss is more complicated. The dielectric loss of the nanocomposites exhibits large variation as the volume fraction of CCTO increases.

At low frequency $(<1 \mathrm{kHz})$, it seems that the dielectric loss increase due to increase the content of CCTO. The dielectric loss at high frequencies is due to the relaxation process in the polymer matrix [13].

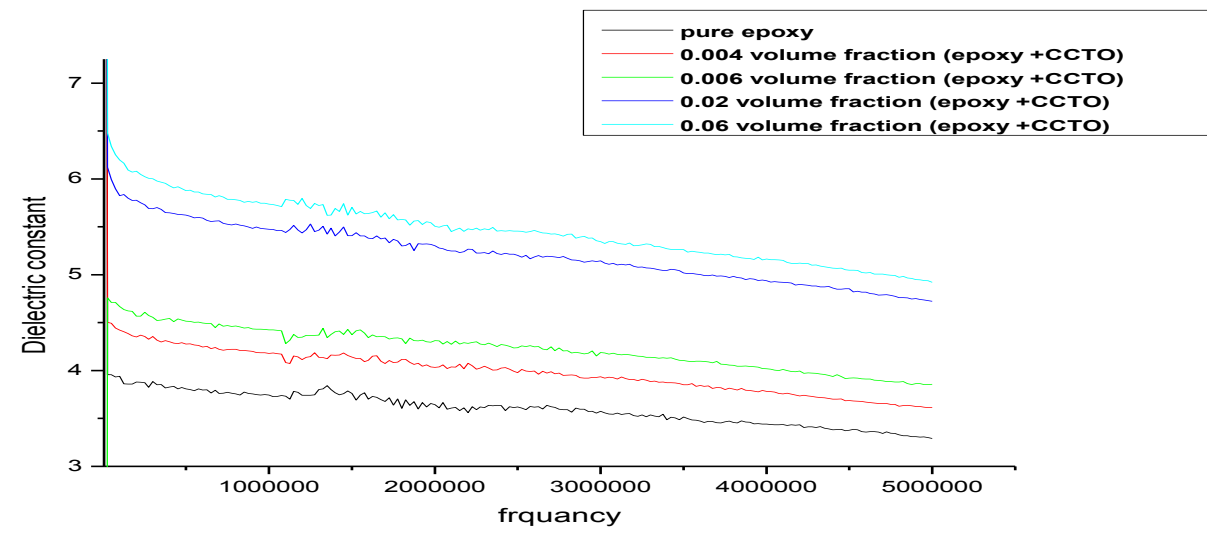

(a)

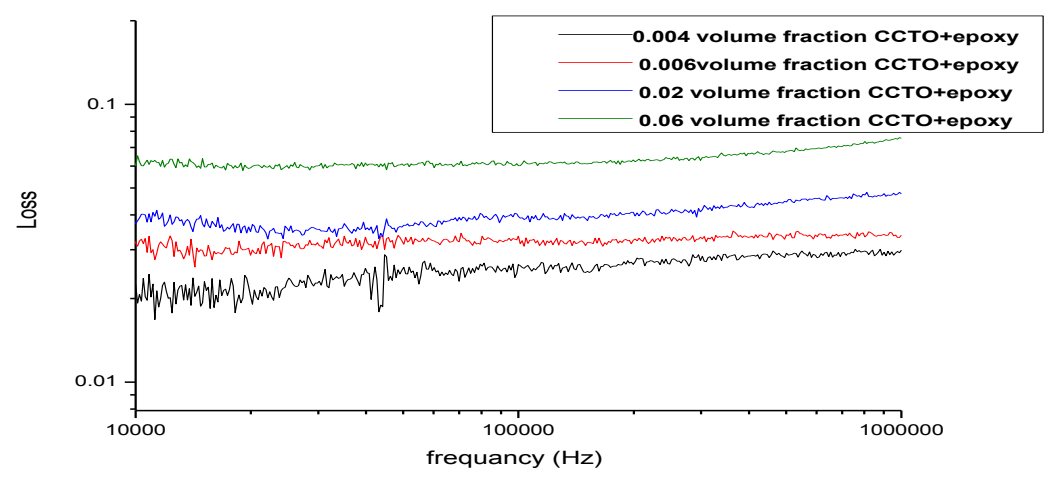

(b)

Fig.(3) : calcined Powder CCTO at $900^{\circ} \mathrm{C}$ (a)dielectric constant versus frequency (b) loss versus frequency

Used dielectric constants calculated of CCTO based on various models are also included in the figure (3). According to the well-known Maxwell-Garnett model, the effective dielectric constant (of above mentioned composite is given by,

$$
\in=\in 1\left\{1+\frac{n q(\in 2-\in 1)}{n \in 1+(\in 2-\in 1)(1-q)}\right\}
$$

Where:

$\epsilon=$ dielectric constant of mixture (CCTO/ epoxy)

$\in 1=$ dielectric constant of epoxy

$\in 2=$ dielectric constant of CCTO

$\mathrm{n}=$ is the parameter related to the geometry of the ceramic particles [7] and is equal (10.2).

$q=$ volume friction

In order to study the composite dependence of the dielectric constant for these composites, the dielectric constant at different frequency are plotted against the content of CCTO as shown in Fig.(4a).

The dielectric constant of the nanocomposites exhibits a much more gradual growth. This result indicates that the increase of the dielectric constant is possible related to the interface areas introduced by the CCTO particles. It appears that the dielectric constant of composite is almost linearly dependent on the constant of CCTO particles. This composition dependent of dielectric constant was also reported in Ref. [14] in order ceramicpolymer composites.

The data shown in fig.(4b) indicates that as the uniformity of the composite is improved, the volume fraction of CCTO increases, while the dielectric loss increase slightly at frequency. 


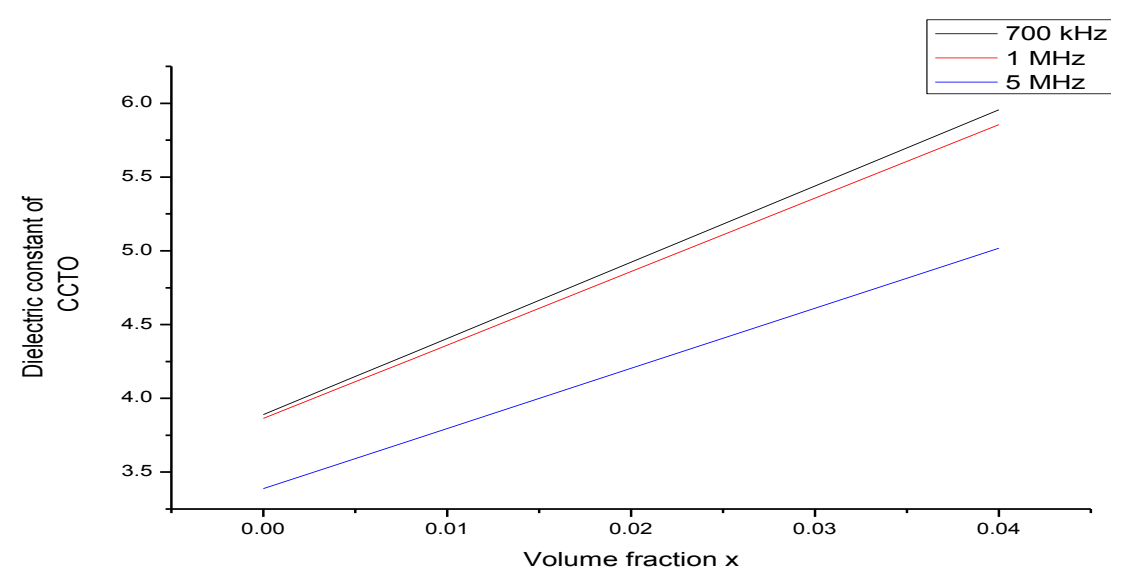

(a)

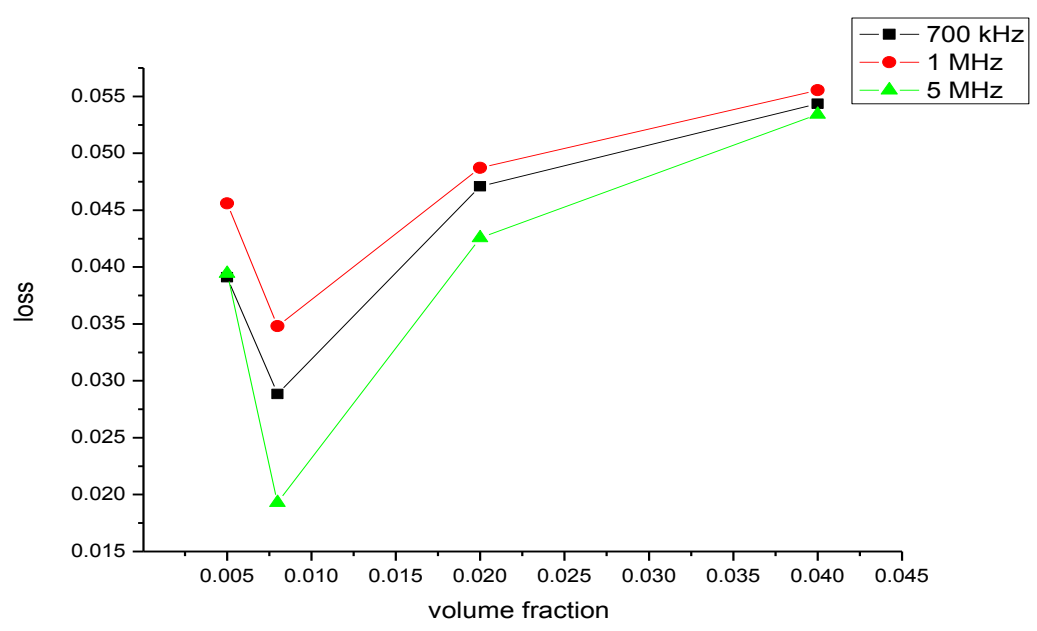

(b)

Fig.(4) calcined Powder CCTO at $900 \mathrm{oC}$ a) Dielectric constant as a function of volume fraction with different frequency, b) losses as a function of volume fraction with different frequency

The temperature dependence of dielectric properties was determined for all the prepared composites as shown in Fig 6. Although the dielectric constant of the composites with different contents of CCTO is different, all the composites show the same dependence of the dielectric constant and loss on the temperature. A typical set of results is shown in fig.(6). At this phase transition temperature, the composition exhibits a dielectric constant of 150 at $10 \mathrm{kHz}$ with a loss less than 0.1 shown fig. (6a).

It is also shown that the earlier reports which exhibit a step like increase from a low to high temperature of the order of 100 values of dielectric constant, is disappeared. This is because the effect of dielectric constant of epoxy is dominated with the small content of CCTO. 


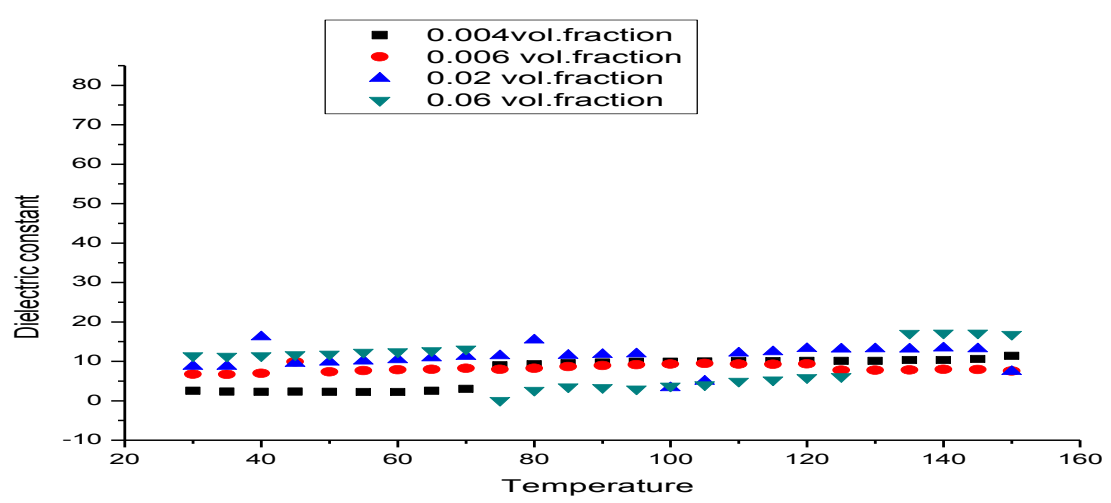

(a)

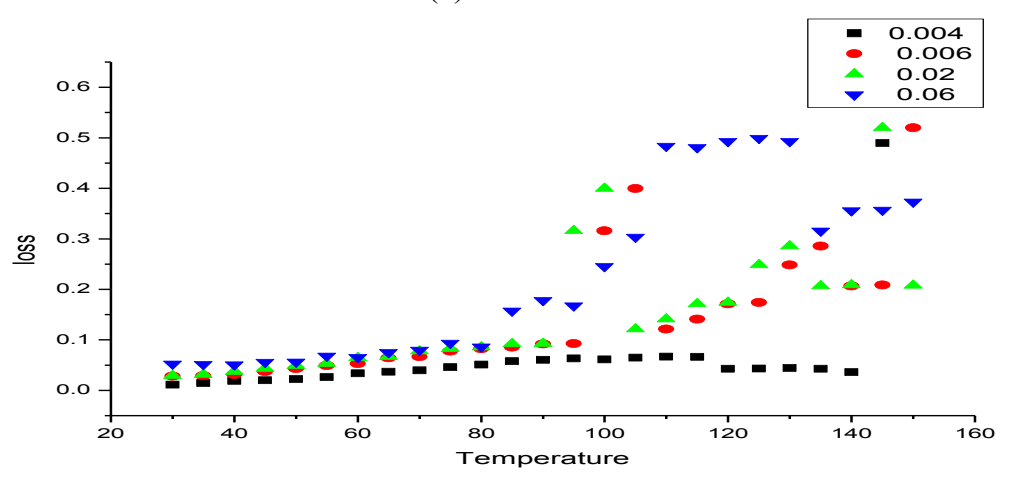

(b)

Fig.(6) calcined Powder $\mathrm{CCTO}$ at $950^{\circ} \mathrm{C}$ a) temperature dependence of dielectric constant at different volume fraction and at $10 \mathrm{kHz}, \mathrm{b}$ ) temperature dependence of loss at different volume fraction and at $10 \mathrm{kHz}$

\section{Conclusion}

Results on the characterization of nanostructure $\mathrm{CaCu} 3 \mathrm{Ti}$ 4012, prepared from an oxalate precursor and heat treated at $900^{\circ} \mathrm{C}$ and $950^{\circ} \mathrm{C}$, are investigated.

Using different content of CCTO prepared oxalate method with Epoxy as a matrix and studying of its dielectric constant and dielectric loss, there is a significant change in them for all content values. It is shown that the nanostructure and the electrical properties of CCTO ceramics are strongly dependent on processing conditions. The Maxwell-Wagner model has recently been adopted to explain the high permittivity observed in CCTO/Epoxy composite.

The frequency and temperature dependencies of the dielectric constant and dielectric loss of the nanocomposites suggest that the introduced CCTO phase contribute to the improvement of the dielectric responses.

\section{Reference}

[1]. M.A. Subramanian, L.D. Duan, B.A. Reisner, and A.W. Sleight, High dielectric constant in ACu3Ti4O12 and $\mathrm{ACu}_{3} \mathrm{Ti}_{3} \mathrm{FeO}_{12} \mathrm{phases}$ Journal Solid State Chemistry , 151, 2000, 323-325.

[2]. C.C. Homes, Vogt, T. Shapiro, S. Wakimoto, and A.P. Ramirez, Optical Response of High-Dielectric-Constant Perovskite-Related Oxide, Science, 293, 2001, 673-676.

[3]. D.C. Sinclair, T.B.Adams, F.D. Morrison, and A.R. West, $\mathrm{CaCu}_{3} \mathrm{Ti}_{4} \mathrm{O}_{12}$ : One-step internal Barrier Layer Capacitor.,Applied physics . Lett. 80(12), 2002, 2153-2155.

[4]. Li, W. Schwartz, and R.W. , Maxwell-Wagner relaxations and their contributions to the high permittivity of calcium copper titanate ceramics, phys. Rev B 75(1), 2007, 012104.

[5]. P. Lunken Heimer, V. Bobnar, A.V .Pronin, A.I. Ritus, A.A. Volkov, and A.Loidl, Origin of apparent colossal dielectric constants, Pysical Revlew, B 66, 2002, 052105.

[6]. P. Lunken Heimer, R. Fichtl , S.G. Ebbinghaus,and A.Loidl, Non-intrinsic origin of the Colossal Dielectric Constants in CaCu3Ti4O12, Phys. Rev. B70, 2004, 172102 .

[7]. R.N. Choundhary, and U.Bhunia, Structural, dielectric and electrical properties of $\mathrm{ACu}_{3} \mathrm{Ti}_{3} \mathrm{FeO}_{12}(\mathrm{~A}=\mathrm{Ca}, \mathrm{Sr}$ and $\mathrm{Ba})$, Journal of Materials Science37, 2002, 5177-5182.

[8]. R.K. Grubbs, E.L. Venturini, P.G. Clem, J.J. Richardson, B.A. Tuittle, and G.A. Samara, Dielectric and magnetic properties of Feand $\mathrm{Nb}$-doped $\mathrm{CaCu}_{3} \mathrm{Ti}_{4} \mathrm{O}_{12}$, phys. Rev. B72(10), 2005, 104111 .

[9]. L.He, J.B. Neaton, M.H. Cohen, D.Vanderbit, and C.C. Homes, First-principles study of the structure and lattice dielectric response of $\mathrm{CaCu}_{3} \mathrm{Ti}_{4} \mathrm{O}_{12}$ Phys. Rev. B 65(21), 2002, 214112. 
[10]. P.Lunkenheimer, R.Ficht, S.G. Ebbinghaus, and A.Loidl, Evidence for power-law frequency dependence of intrinsic dielectric response in the CaCu3Ti4O12, Phys. Rev. B70, 2004, 172102.

[11]. L.Liu, H.Fan, P.Fang, and L.Jin, Fast densification and electrical conductivity of yttriastabiize dzirconianano ceramics ,Solid State Comm.142, 2007, 573-576.

[12]. A.P. Ramirez, M.A. Subramanian, M.Gardel, G.Blumberg, D.Li, T.Voget, and S.M. Shapiro, Giant dielectric constant response in a copper-titanate, Solid State Communications, (115), 2000, 217-220.

[13]. Z.Y. Cheng, Q.M. Zhang, and F.B. Bateman, Dielectric relaxation behavior and its relation to microstructure in relaxor ferroelectric polymers: High-energy electron irradiated poly(vinylidene fluoride-trifluoroethylene) copolymers, Journal Applied Physics, 92(11), 2002, 6749.

[14]. X. Zhang, C. L. Pint, M. H. Lee, B. E. Schubert, A. Jamshidi, K. Takei, H. Ko, A. Gillies, R. Bardhan, J. J. Urban, M. Wu, R. Fearing, and A. Javey. ,Optically- and Thermally-Responsive Programmable Materials Based on Carbon Nanotube-Hydrogel Polymer Composites, Nano Letters, 11, 2011, 3239-3244. 